\title{
Images
}

\section{Unusual airway injury following a motor vehicle collision}

\author{
Christopher Sampson
}

A 16-year-old male presented to the emergency department following a single-truck motor vehicle collision. The patient was the driver of an older model pickup truck that he lost control of while driving and went off of the road. He was restrained with a lap belt only, given the age of the vehicle. His only complaint at the presenting hospital was left-sided neck pain and hoarseness.

Direct visualization of his airway using fiber optics is shown in Figure 1. Computed tomography imaging was obtained (Figure 2). The diagnosis was laryngeal injury resulting in avulsion of the left false cord.

\section{DISCUSSION}

Blunt neck trauma occurs in 5\% of traumas and is more common than penetrating neck injuries. ${ }^{1}$ The most common mechanism is a motor vehicle collision where rapid acceleration or deceleration occurs. Laryngotracheal injuries in blunt neck trauma are second only to intracranial hemorrhage as cause of death among patients with head and neck trauma. Mortality has been reported from $2 \%$ to $15 \%$ and increases with advancing age. ${ }^{2}$ The most common presenting symptom in these patients is hoarseness. ${ }^{3}$

Airway control in these patients should be a priority. ${ }^{4}$ Cervical spine control should be maintained. Intubation may be difficult, secondary to additional facial injuries. High suspicion for pharyngeal, esophageal, cervical spine, and head injuries needs to be maintained.

This patient was taken to the operating room for tracheostomy placement and repair of laryngeal injury and mandibular fixation. He did well postoperatively, and the tracheostomy was eventually removed.

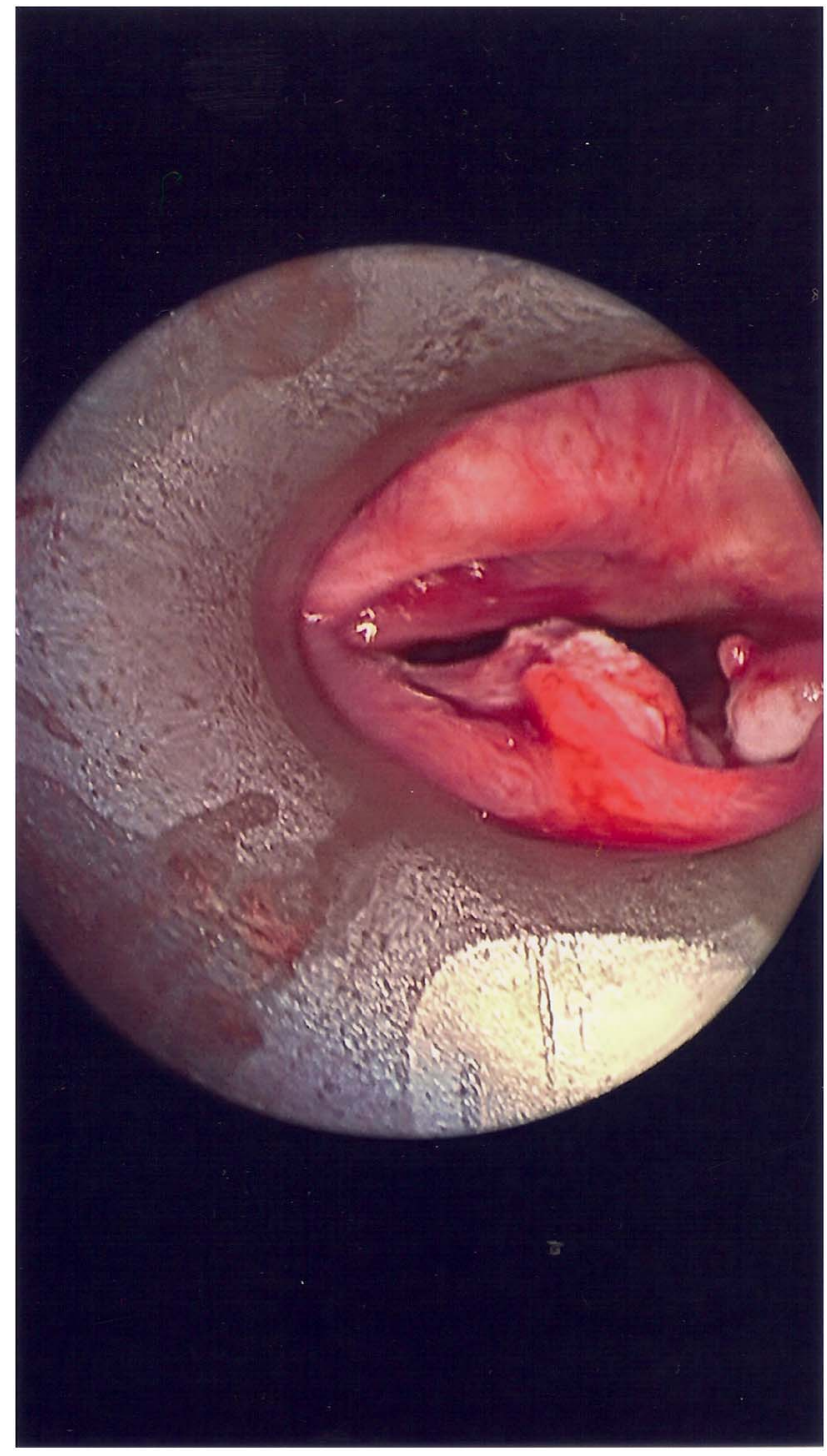

Figure 1. Direct visualization of patient airway using fiber optics.

From the From Department of Emargency Medicine, Columbia, United States.

Correspondence to: Dr. Christopher Sampson, Department of Emergency Medicine, University of Missouri, 1 Hospital Drive DC 029.1, Columbia, MO 65212. Email: sampsoncs@ @ealth.missouri.edu 


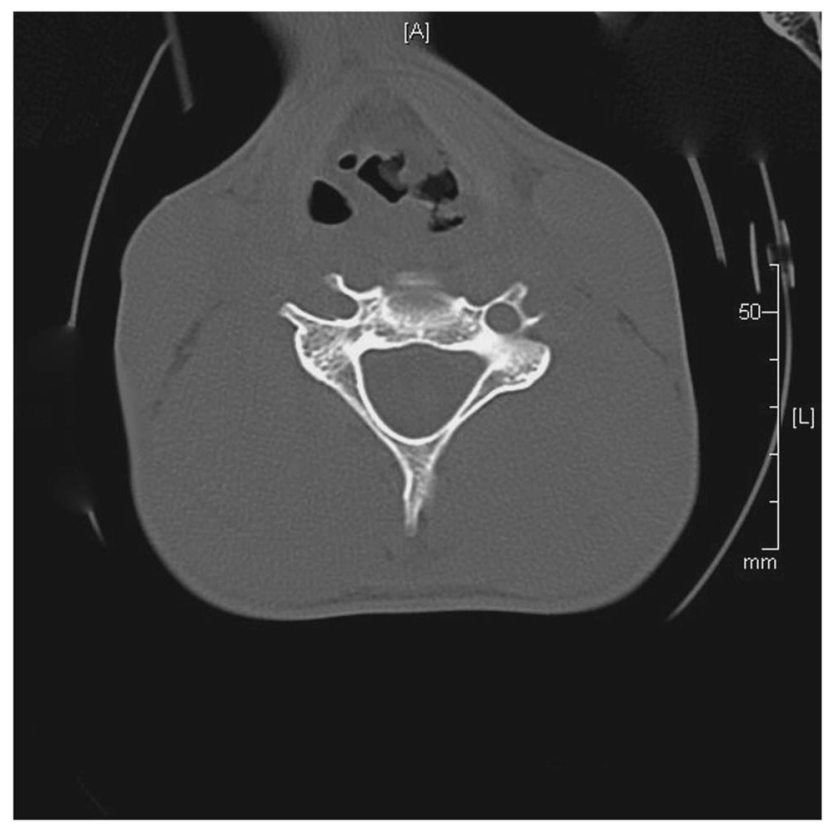

\section{REFERENCES}

1. Levy D. Neck trauma. eMedicine. Available at: http://emedicine. medscape.com/article/827223 (accessed February 18, 2014).

2. Jewett BS, William SW, Rutledge R. External laryngeal trauma analysis of 392 patients. Arch Otolaryngol Head Neck Surg 1999;125:877-80.

3. Juutilainen M, Vintturi J, Robinson S, et al. Laryngeal fractures: clinical findings and considerations on suboptimal outcome. Acta Otolaryngol 2008;128:213-8.

4. Rathlev NK, Medzon R, Bracken M. Evaluation and management of neck trauma. Emerg Med Clin North Am 2007;25(3):679-94; viii.

Figure 2. Computed tomography scan of laryngeal injury resulting in avulsion of the left false cord. 